\title{
Is the role of Health Extension Workers in the delivery of maternal and child health care services a significant attribute? The case of Dale district, southern Ethiopia
}

Abel Negussie* and Gedion Girma

\begin{abstract}
Background: The Health Extension Program (HEP) is one of the most innovative community based health program launched by the Ethiopian Federal Ministry of Health to make health services accessible to rural communities by setting-out women Health Extension Workers (HEWs) in rural Health Posts. The HEWs are premised to provide basic, largely preventive, primary health services to rural villages and the program gives special attention to children and mothers. The objective of the study was to assess the contribution made by the Health Extension Workers in maternal and child health care service delivery in Dale district, southern Ethiopia.
\end{abstract}

Methods: Using a community based cross-sectional data; the study assessed the status of mother's health service utilization and estimated the role of HEWs in maternal and child health care delivery. Mothers of reproductive age (15-49), having at least one under-five age child, were eligible for the study. The total sample size was 617 and systemic random sampling method was used to select the study subjects from each randomly selected kebeles (lower administrative units). Structured questionnaire was applied to collect data through interviewing of the selected mothers and the data were analysed using SPSS version 16 statistical software.

Results: Health Posts are important health care delivery settings and their share from the overall service delivery of ANC, Family planning and child treatment services were pivotal. However, overall service coverage of ANC (four and more visits), delivery and PNC services were low in the district as compared to the national status; and the input from the HEWs, in this regard, was unsatisfactory. The number of home visits was also inadequate for the necessary support of the mothers. The results of the multiple logistic regression indicated that mothers who listen to the radio (AOR 4.62; $\mathrm{Cl}$ 1.66-12.85) and who had received information about the $\mathrm{MCH}$ services by HEWs (AOR 2.09; $\mathrm{Cl} 1$. 06-4.14) were significantly associated with good MCH service utilization status.

Conclusion: Health Extension Workers can improve their role in the MCH service delivery in the district by delivering appropriate information about the different available services to the mothers at the community and household level. All concerned bodies, including federal, regional and local governments should support the efforts of HEWs and need to address the challenges for poor performance areas of the HEWs in MCH service delivery.

Keywords: Health Extension Workers, MCH service utilization, Southern Ethiopia

\footnotetext{
* Correspondence: abelnegussie@ymail.com

Yirgalem Hospital Medical College, Yirgalem, Ethiopia
} 


\section{Background}

In Ethiopia, pregnancy remains to be the leading cause of death of women in their reproductive years and the rate of under-5 and maternal mortality are among the highest in the world estimated at 67 deaths per 1000 live births and 412 deaths per 100,000 live births, respectively. Each year an estimated 22,000 women and 88,000 new-borns die from complications related to childbirth, mostly because of the large majority of the deliveries occur at home. In the last decade, the top four causes of maternal mortality were obstructed labor/uterine rupture, haemorrhage, hypertensive disorders of pregnancy and sepsis/infection [1, 2].

Moreover, Ethiopia is among the six countries that account for $50 \%$ of under-five child mortality globally, with 194,000 deaths every year. More than one third of the deaths are largely due to communicable diseases that could easily be prevented and treated using affordable and low-technology interventions. Nearly $68 \%$ of underfive deaths are attributed to pneumonia (21\%); diarrhoea (14\%); neonatal conditions such as prematurity (15\%) and birth asphyxia (10\%); measles (4\%); malaria (2\%) and HIV (2\%) [3-5].

To address these maternal and child health problems and to increase access to health facility, the government of Ethiopia launched the Health Extension Program (HEP) in 2003; an innovative way of scaling up the delivery of basic and essential promotive, preventive and selected high impact curative health services targeting the household and community level by setting out women Health Extension Workers (HEWs) in rural Health Posts (HPs) [6-8].

The primary purpose of the HEP is to improve access and utilization of health care particularly for children and mothers. The program approach is based on the widely influential model known as the diffusion model, which holds that community behaviour can be changed step by step; training early adopters first, and then moving to the next group that is ready to change. Similarly, the HEP is designed to improve the health status of families, with their full participation, using local technologies and the community's skill and knowledge $[6,7,9]$.

A concerted effort by the government to expand the primary health care system and emphasize on preventive, promotive and basic curative health services resulted in a positive improvements in the health coverage and utilization; and consequently, maternal mortality ratio has shown a decreasing trend from the year 2000 estimate of 871 deaths per 100,000 live births to 412 deaths per 100,000 live births in 2016; and between 2000 and 2016, infant mortality has declined from 97 deaths per 1000 live births to 48 deaths per 1000 live births and under-five mortality from 166 deaths per 1000 live births to 67 deaths per 1000 live births $[1,10]$.
Based on the United Nations Inter-agency Group for Child Mortality Estimation (UN IGME) 2013 report, despite Sub-Saharan Africa's relatively high rates of under-five mortality, there are signs of progress in the region. The rate of decline in under-five mortality has accelerated over time - from $0.8 \%$ a year over 1990 1995 to $4.1 \%$ a year over 2005-2012. According to the report, higher annual rates of reduction (5\% per year) was observed in Ethiopia, which had reduced under-five mortality by more than a half from 1990 to 2012 (67\%); and in all these progresses in the reduction of maternal and under-five child mortality rates, an important research question remains is that 'How much the role of HEWs is noteworthy in the process of maternal and child health care service delivery?' [11]. Previous published assessments of the roles of HEWs or the HEP were not inclusive of all major $\mathrm{MCH}$ components and the efforts made by the HEWs were not examined with the context of overall $\mathrm{MCH}$ service delivery [12-14]. In addition, the level of involvement of the HEWs in $\mathrm{MCH}$ service delivery was not assessed in the study area using a community based data. The objective of the study was to assess the level of contribution made by the Health Extension Workers in maternal and child health care service delivery in Dale district, southern Ethiopia.

\section{Methods \\ Study design and setting}

A community based cross-sectional survey was undertaken from May 24 to June 24, 2015 to assess the role of HEWs in $\mathrm{MCH}$ service delivery in rural villages of Dale district, Sidama zone, SNNPRS (Southern Nations, Nationalities and Peoples Regional State), Ethiopia. Dale district is one of the 19 districts in Sidama zone, and located $42 \mathrm{kms}$ far from Hawassa town (capital city of SNNPRS) and $302 \mathrm{kms}$ far from Addis Ababa town. It is divided into 3 urban and 33 rural kebeles (lower administrative units) and the total population of women within the reproductive age group in the area is estimated to be 61,639. Health Posts, which are headed and staffed by HEWs, represent the primary point of care.

\section{Study participants}

Randomly selected mothers with under-five children who were willing and healthy enough to be interviewed were identified to participate in the survey. We employed the Statcalc sample size calculation for crosssectional study using EPI-info version 3.5.4 to determine the sample size for our study. The total sample size was 617 and it was determined with an assumption of: 95\% confidence interval, margin of sampling error tolerated $5 \%$, taking contraceptive prevalence rate of $25.8 \%$ $(P=0.25)$ for SNNPRS as key variable [15] and 5\% non- 
response rate. Design effect of two was also considered because of the two sampling stages.

A two stage sampling technique was used to get representative mothers. Out of the total kebeles, 10 kebeles were selected randomly using simple random sampling (lottery) method and the required sample size for each selected kebele was taken according to the population size of each kebele. To select households with representative mothers, a map of each kebele was taken and the direction to start the first household was located using lottery method; then it was started from the first household and every fourth household was visited, by using a systematic random sampling method. If a home didn't have the appropriate mother for the interview, the next home was visited until the sample required was obtained.

\section{Data collection procedure}

Data was collected on mother's utilization of family planning, ANC, delivery, PNC and child health care services. The questionnaire was initially developed in English and then translated to the local language, 'Sidamigna'. Before the actual data collection, the questionnaire was pre-tested in other similar nearby district, to assure clarity of the concepts for respondents. The data were collected by twelve data collectors who had first degree and experience of doing questionnaire interviews; and training was given for the data collectors on details of the questionnaire. Responses of randomly selected questionnaires were re-checked by supervisors in the field to ensure rigor in the study.

\section{Data processing and analysis}

The data were checked for its completeness; and were coded, entered, cleaned, explored and finally analysed using SPSS-version 16 statistical software. Descriptive statistics were used to summarize the data, and a bivariate analysis was carried out using binary logistic regression analysis to describe associations between exposure variables and $\mathrm{MCH}$ service utilization status of mothers with a significance level of $p$-value $\leq 0.05$. In the multivariate analysis, potential independent variables were entered into the model; and a backward elimination procedure was applied and a $p$-value $\leq 0.05$ was considered to identify predictors of good $\mathrm{MCH}$ service utilization.

\section{Operational definitions}

Utilization of maternal and child health services were collected using the following variables:

- Family planning: If the mother has been using any contraceptive method during the interview period (current utilization).

- Antenatal care (ANC): If the mother attended a health facility for ANC, at least four times in her last pregnancy.
- Institutional delivery: If the mother gave birth in a health facility for her last child.

- Postnatal care (PNC): If the mother visited a Health Centre/Health Post within 24 h - 42 days of the birth of her last child.

- Immunization: If the mother had vaccinated her last under-five child for Penta 3 by validating mother's verbal report with the records in the immunization card.

- Acute respiratory infection (ARI) treatment: If the youngest under-five child treated for symptoms of ARI in the 2 weeks preceding the survey.

- Diarrhoea treatment: If the youngest under-five child treated for diarrhoea in the 2 weeks preceding the survey.

- Fever treatment: If the youngest under-five child treated for fever in the 2 weeks preceding the survey.

- MCH service utilization: The dependent variable was computed by combining the utilization status of the above eight $\mathrm{MCH}$ services. Using the mean (2.63) as a cut-off point, we had categorized utilization of maternal health services into two categories. Mothers who had utilized three and more maternal health services were defined as having 'Good utilization' of $\mathrm{MCH}$ services, while those who had utilized less than three were considered as having 'Poor utilization' of $\mathrm{MCH}$ services.

- Information delivery by HEWs about MCH services: Mothers were asked whether they have information or not about the eight $\mathrm{MCH}$ services given by HEWs. Mothers who had information on at least two $\mathrm{MCH}$ services were defined as having 'good information', while those who had no information or had information for only one $\mathrm{MCH}$ service were considered as having 'poor information'.

- Counselling and follow up: If the mother took counselling and followed for continuous utilization of at least one $\mathrm{MCH}$ service.

- Service delivery approach: There were six items to measure the different perceived perspectives of the $\mathrm{MCH}$ service delivery approach. These were, giving complete explanation about the service/ health problem, friendly approach during service delivery, making helpful suggestions, discuss treatment/service options, giving of the health service/treatment with respect; and helping the mother to understand her own/her child's health condition. Two and more positive answers were considered as the mother was satisfied with the service delivery approach.

- A model family: A family which has fulfilled and implemented all packages of the HEP. 


\section{Results}

A total of 613 mothers with under-five children, were interviewed and the response rate was $99.4 \%$. The majority of the respondents was found to be Sidama by ethnicity, 583 (95.1\%), Protestant by religion $(83.4 \%)$, and $32 \%$ were in the age group of $25-$ 29 years during the delivery of their last child. Furthermore, the majority of the respondents were married accounting 94.4\%; and the mean age of the interviewed mothers was 28 years. Of the total mothers, $83.4 \%$ were house wives/not having paid work and $12.2 \%$ were farmers. Regarding the educational background of the mothers, $23.4 \%$ of the mothers didn't ever attended school and $63.6 \%$ of them attended only primary education. Most of the respondents $(83 \%)$ had no access to listen to the radio and $54 \%$ of the mothers were graduated as a model household (Table 1).

\section{MCH service utilization status}

Most of the mothers (95.4\%) were not pregnant during the survey and want to have a baby $(60.9 \%)$. Of the total mothers, $58.9 \%$ had a history of ANC follow-up during their last pregnancy and $14.3 \%$ of them had attended at least the recommended four visits. A large proportion of mothers (89.6\%) who attended ANC follow-up had received tetanus toxoid injections and about half of them had received only one injection. Out of the total mothers, $22.5 \%$ of them had delivered their last child at health institutions and more than three fourth of them gave birth at home. Among the mothers who gave birth at health institutions, $26.7 \%$ of them had delivered their last child by caesarean section.

According to the mothers' report, more than one third of the mothers (37\%) had attended PNC service within 6 weeks after delivery. $70.5 \%$ of the mothers were currently using family planning methods and $40.8 \%$ of the mothers had vaccinated their child for Penta 3 vaccine. Regarding seeking care for under-five children with a history of illness, $52.3 \%, 38.7 \%$ and $39.3 \%$ were treated for diarrhoea, acute respiratory infections and Acute Febrile Illnesses (AFI), respectively (Table 2).

Role of Health Extension Workers in $\mathrm{MCH}$ service delivery Of the total mothers, 428 (69.82\%) mothers visited Health Post for at least one health service of their own or their last child. Health Post accounts' for $50 \%$ of ANC follow up, $55.6 \%$ of family planning and $3.2 \%$ of delivery services; and $27.5 \%$ and $48 \%$ of diarrhoea and AFI treatment services, respectively. Private clinics also have an important share in the delivery of $\mathrm{MCH}$ services, accounting $12.5 \%$ of $\mathrm{ANC}$
Table 1 Socio-demographic characteristics of mothers in Dale district, southern Ethiopia, 2015

\begin{tabular}{|c|c|c|c|}
\hline Variables & Category & Frequency & Percent (\%) \\
\hline \multirow[t]{6}{*}{ Maternal age } & $15-19$ & 85 & 14.5 \\
\hline & $20-24$ & 183 & 31.3 \\
\hline & $25-29$ & 187 & 32.0 \\
\hline & $30-34$ & 86 & 14.7 \\
\hline & $35-39$ & 30 & 5.1 \\
\hline & $>40$ & 14 & 2.4 \\
\hline \multirow[t]{4}{*}{ Mother's educational status } & Illiterate & 143 & 23.4 \\
\hline & $\begin{array}{l}\text { Primary } \\
\text { education }\end{array}$ & 388 & 63.6 \\
\hline & $\begin{array}{l}\text { Secondary } \\
\text { education }\end{array}$ & 68 & 11.1 \\
\hline & Higher education & 11 & 1.8 \\
\hline \multirow[t]{3}{*}{ Marital status } & Married & 576 & 94.4 \\
\hline & Widowed & 21 & 3.4 \\
\hline & Divorced & 13 & 2.1 \\
\hline \multirow{5}{*}{$\begin{array}{l}\text { Age of the index child } \\
\text { (months) }\end{array}$} & Neonate & 58 & 9.4 \\
\hline & $1-6$ & 176 & 28.7 \\
\hline & $7-11$ & 88 & 14.3 \\
\hline & $12-23$ & 99 & 16.1 \\
\hline & $24-59$ & 192 & 31.3 \\
\hline \multirow[t]{3}{*}{ Ethnicity } & Sidama & 583 & 95.1 \\
\hline & Amhara & 14 & 2.3 \\
\hline & Other & 16 & 2.7 \\
\hline \multirow[t]{4}{*}{ Religion } & Protestant & 511 & 83.4 \\
\hline & Orthodox & 22 & 3.6 \\
\hline & Catholic & 63 & 10.3 \\
\hline & Muslim & 17 & 2.8 \\
\hline \multirow[t]{3}{*}{ Occupational status } & Housewife & 511 & 83.4 \\
\hline & Farmer & 75 & 12.2 \\
\hline & Other & 27 & 4.4 \\
\hline \multirow[t]{2}{*}{ Listen to the radio } & Yes & 101 & 17 \\
\hline & No & 492 & 83 \\
\hline \multirow{2}{*}{$\begin{array}{l}\text { Graduated as a model } \\
\text { family }\end{array}$} & Yes & 331 & 54 \\
\hline & No & 282 & 46 \\
\hline
\end{tabular}

follow up, 25.9\% of AFI treatment and 5.1\% of family planning services (Table 3 ).

Out of the mothers who knew $\mathrm{MCH}$ services are given in Health Posts, the following proportion of mothers knew that the services are available in HPs; $56.8 \%$ - family planning, 51.5\% - ANC, 44.4\% - delivery, 45.6\% - PNC, 80.5\% - immunization, $60.2 \%$ - growth monitoring and $45.5 \%$ sick baby care services (Table 4). Moreover, 195 (74.4\%) of the mothers also described that HEWs were available at HPs during their last visit for $\mathrm{MCH}$ services (Fig. 1). Within the preceding 6 months of the survey, 10.9\% of 
Table $2 \mathrm{MCH}$ service utilization status of mothers in Dale district, southern Ethiopia, 2015

\begin{tabular}{|c|c|c|c|}
\hline $\mathrm{MCH}$ services & $\begin{array}{l}\text { Service } \\
\text { utilization status }\end{array}$ & Frequency & Percent (\%) \\
\hline \multirow[t]{2}{*}{ Antenatal care } & Yes & 88 & 14.3 \\
\hline & No & 525 & 85.6 \\
\hline \multirow[t]{2}{*}{ Institutional delivery } & Yes & 138 & 22.5 \\
\hline & No & 475 & 77.5 \\
\hline \multirow[t]{2}{*}{ Postnatal care } & Yes & 227 & 37 \\
\hline & No & 386 & 63 \\
\hline \multirow[t]{2}{*}{ Family planning } & Yes & 428 & 70.5 \\
\hline & No & 179 & 29.5 \\
\hline \multirow[t]{2}{*}{ EPI } & Yes & 250 & 40.8 \\
\hline & No & 362 & 59.2 \\
\hline \multirow{2}{*}{$\begin{array}{l}\text { Diarrhoea treatment for }<5 \\
\text { children }\end{array}$} & Yes & 69 & 52.3 \\
\hline & No & 63 & 47.7 \\
\hline \multirow{2}{*}{$\begin{array}{l}\text { Acute Respiratory Infection } \\
\text { (ARI) treatment }\end{array}$} & Yes & 63 & 38.7 \\
\hline & No & 100 & 61.3 \\
\hline \multirow{2}{*}{$\begin{array}{l}\text { Acute Febrile IIIness (AFI) } \\
\text { treatment }\end{array}$} & Yes & 77 & 39.3 \\
\hline & No & 119 & 60.7 \\
\hline
\end{tabular}

Table 3 Place of receiving MCH services in Dale district, southern Ethiopia, 2015

\begin{tabular}{llll}
\hline MCH services & $\begin{array}{l}\text { Place where the } \\
\text { service utilized }\end{array}$ & Frequency & Percent (\%) \\
\hline Antenatal care & Health Post & 44 & 50 \\
& Health centre & 29 & 32.9 \\
& Hospital & 4 & 4.5 \\
& Private clinic & 11 & 12.5 \\
Delivery & Home & 475 & 77.5 \\
& Health Post & 20 & 3.2 \\
& Health centre & 75 & 12.2 \\
& Hospital & 29 & 4.7 \\
& Private clinic & 14 & 2.2 \\
Family planning & Health Post & 238 & 55.6 \\
& Health centre & 165 & 38.5 \\
& Hospital & 3 & 0.7 \\
& Private clinic & 22 & 5.1 \\
& Health Post & 19 & 27.5 \\
Diarrhoea treatment for & Health Centre & 43 & 62.3 \\
<5 children & Hospital & 7 & 10.1 \\
& Health Post & 37 & 48 \\
Acute Febrile IIIness & Health Centre & 15 & 19.4 \\
(AFI) treatment & Hospital & 5 & 6.5 \\
& Private clinic & 20 & 25.9 \\
\hline
\end{tabular}

Table 4 Information about the different MCH services given by HEWs in Dale district, southern Ethiopia, 2015

\begin{tabular}{llll}
\hline Information about the MCH services & Category & Frequency & Percent (\%) \\
\hline Knew family planning as MCH & Yes & 184 & 56.8 \\
service & No & 91 & 28.1 \\
Knew ANC as MCH service & Yes & 132 & 51.5 \\
& No & 124 & 48.5 \\
Knew institutional delivery as MCH & Yes & 110 & 44.4 \\
service & No & 138 & 55.6 \\
Knew PNC as MCH service & Yes & 117 & 45.6 \\
& No & 139 & 54.3 \\
Knew immunization as MCH service & Yes & 210 & 80.5 \\
& No & 51 & 19.5 \\
Knew growth monitoring as MCH & Yes & 159 & 60.2 \\
service & No & 105 & 39.7 \\
Knew sick baby care as MCH service & Yes & 117 & 45.5 \\
& No & 140 & 54.5 \\
Knew diarrhoea treatment as MCH & Yes & 106 & 39 \\
service & No & 166 & 61 \\
\hline
\end{tabular}

the mothers were visited by HEWs and received $\mathrm{MCH}$ services at their home (Fig. 2).

Based on the mothers' report; $61.1 \%$ of the mothers indicated that they had gotten a complete explanation of her own/child's health condition from the HEWs, 56.7\% and $54.8 \%$ stated that the HEWs were friendly and helped to understand their own/their child's health condition, respectively. Moreover, $50.5 \%$ of the mothers reported that HEWs had made helpful suggestions about the prevention of maternal/child illnesses (Table 5).

\section{Determinant factors of good MCH service utilization status}

Determinant factors of good $\mathrm{MCH}$ service utilization were assessed with the perspective of HEW's key roles and activities. Selected socio-demographic

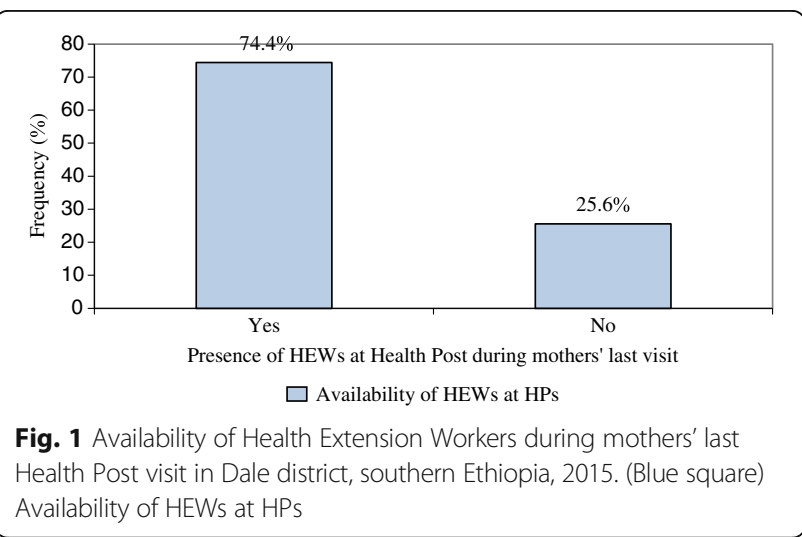




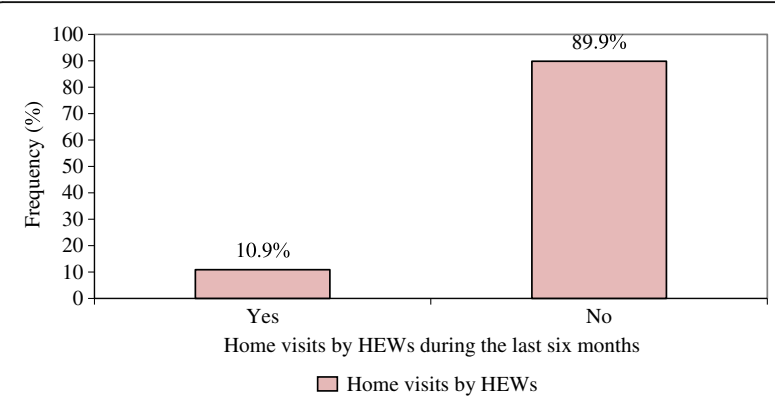

Fig. 2 Home visits by Health Extension Workers (HEWs) during the last 6 months in Dale district, southern Ethiopia, 2015. (Red square) Home visits by HEWs

variables and variables which indicate major activities of the HEWs were assessed to determine their association with good service utilization status. Mother's educational status, listening to the radio, information delivery by HEWs about $\mathrm{MCH}$ services and home visits in the last 6 months by HEWs were significant in the bivariate analysis with $p$-value $\leq 0.05$ (Table 6).

In order to identify predictors of good $\mathrm{MCH}$ service utilization, the possible confounding effect was controlled using multiple logistic regression analysis; and found that mothers who listen to the radio (AOR 4.62; CI 1.66-12.85) and who had received information about MCH services by HEWs (AOR 2.09; CI 1.06-4.14) were more likely to use $\mathrm{MCH}$ services than mothers who had not (Table 7).

\section{Discussion}

The coverage of $\mathrm{MCH}$ service utilization in Dale district had decreased when compared to the national status. For instance, when we take a look at ANC

Table 5 Service delivery approach by HEWs in Dale district, southern Ethiopia, 2015

\begin{tabular}{llll}
\hline Service delivery approach & Category & Frequency & Percent (\%) \\
\hline Gave complete explanation & Yes & 113 & 61.1 \\
Friendly & No & 72 & 38.9 \\
& Yes & 106 & 56.7 \\
Made helpful suggestions & No & 81 & 43.3 \\
& Yes & 92 & 50.5 \\
Treated with respect & No & 90 & 49.5 \\
& Yes & 94 & 51.1 \\
Discuss treatment options & No & 90 & 48.9 \\
& Yes & 99 & 52.9 \\
Help me to understand my/child's & Yes & 87 & 46.5 \\
health condition & No & 84 & 54.8 \\
& & & 45.2 \\
\hline
\end{tabular}

follow up and delivery service coverage; ANC follow up (at least four visits) - it was $14.3 \%$ in the study area and 32\% in EDHS 2016; and institutional delivery $-22.5 \%$ and $28 \%$ in our survey and EDHS 2016, respectively. This may be due to less effect of the HEWs in the district or the reason that the national cumulative report sometimes may not reflect actual district level performances [1].

Mothers had received services primarily from Health Posts for family planning, ANC follow up and AFI treatment services and Health Centres were dominant places of receiving care for institutional delivery, PNC and diarrhoea treatment services. This finding is comparable to other studies done in northern Ethiopia [12, 13].

According to our study, listening to the radio and information delivery about $\mathrm{MCH}$ services by HEWs had significant association with good $\mathrm{MCH}$ service utilization status. The study conducted in Tigray region also showed that listening to the radio had significant association with good $\mathrm{MCH}$ service utilization status [12]. In addition, an interventional study conducted in Kenya from 2008 to 2009 revealed that Community Health Workers' (CHWs) information delivery to mothers about $\mathrm{MCH}$ services, through monthly dialogue with the community, had improved proportion of mothers who attend ANC follow up, family planning and immunization services. Furthermore, the study had reported a progress in use of both PNC and institutional delivery services [16].

In support with our finding, ACCESS/MCHIP evaluation survey conducted in Nigeria regarding the program implementation which uses CHWs as a channel for awareness creation on family planning, ANC follow up, institutional delivery and immunization services; showed there was improvement in $\mathrm{MCH}$ service utilization [17]. Moreover, a community-based intervention in Tanzania was designed and implemented by 50 trained safe motherhood promoters (SMPs) with a focus to promote early and complete antenatal care visits; and skilled delivery. The result showed that early ANC booking and deliveries with a skilled attendant had increased significantly [18].

Though our study highlights several potential needs to improve the role of HEWs in the delivery of $\mathrm{MCH}$ services, it has certain limitations. First, as the study is cross-sectional design, no causal conclusions can be drawn. Second, the study relies on selfreported data and a potential recall bias could have been present. Third, the study lacks reference in determining 'Good' and 'Poor' $\mathrm{MCH}$ service utilization cut-off points. 
Table 6 Results from bivariate analysis of different factors for good MCH service utilization status in Dale district, southern Ethiopia, 2015

\begin{tabular}{|c|c|c|c|c|}
\hline Variables & Category & Frequency & COR $(95 \% \mathrm{Cl})$ & $P$-value \\
\hline \multirow[t]{6}{*}{ Maternal age } & $15-19$ & 85 & 1 & \\
\hline & $20-24$ & 183 & $3.30(1.01,10.74)$ & 0.06 \\
\hline & $25-29$ & 187 & $1.78(0.57,5.51)$ & 0.31 \\
\hline & $30-34$ & 86 & $1.98(0.64,6.13)$ & 0.23 \\
\hline & $35-39$ & 30 & $1.97(0.61,6.38)$ & 0.25 \\
\hline & $>40$ & 14 & $1.20(0.32,4.47)$ & 0.78 \\
\hline \multirow[t]{4}{*}{ Mother's educational status } & Illiterate & 143 & 1 & \\
\hline & Primary education & 388 & $0.90(0.53,1.51)$ & 0.69 \\
\hline & Secondary education & 68 & $7.55(0.95,59.61)$ & 0.05 \\
\hline & Higher education & 11 & $0.44(0.30,0.66)$ & $<0.001^{\mathrm{a}}$ \\
\hline \multirow[t]{3}{*}{ Marital status } & Married & 576 & 1 & \\
\hline & Widowed & 21 & $1.26(0.53,3.72)$ & 0.49 \\
\hline & Divorced & 13 & $1.17(0.38,2.87)$ & 0.61 \\
\hline \multirow[t]{3}{*}{ Ethnicity } & Sidama & 583 & 1 & \\
\hline & Amhara & 14 & $1.21(0.26,3.94)$ & 0.53 \\
\hline & Other & 16 & $1.69(0.54,4.42)$ & 0.38 \\
\hline \multirow[t]{4}{*}{ Religion } & Protestant & 511 & 1 & \\
\hline & Orthodox & 22 & $0.41(0.04,4.22)$ & 0.45 \\
\hline & Catholic & 63 & $0.19(0.01,2.15)$ & 0.18 \\
\hline & Muslim & 17 & $0.29(0.02,3.45)$ & 0.33 \\
\hline \multirow[t]{2}{*}{ Listen to the radio } & Yes & 101 & $2.35(1.48,3.71)$ & $<0.001^{a}$ \\
\hline & No & 492 & 1 & \\
\hline \multirow[t]{2}{*}{ Information delivery by HEWs } & Yes & 269 & $2.39(1.72,3.32)$ & $<0.001^{\mathrm{a}}$ \\
\hline & No & 345 & 1 & \\
\hline \multirow[t]{2}{*}{ Home visits by HEWs } & Yes & 67 & $2.12(1.23,3.66)$ & $<0.01^{\mathrm{a}}$ \\
\hline & No & 544 & 1 & \\
\hline \multirow[t]{2}{*}{ Availability of HEWs at HPs } & Yes & 195 & 1 & \\
\hline & No & 67 & $0.64(0.36,1.12)$ & 0.11 \\
\hline \multirow[t]{2}{*}{ Service delivery approach } & Positive & 101 & $1.35(0.75,2.42)$ & 0.31 \\
\hline & Negative & 88 & 1 & \\
\hline \multirow[t]{2}{*}{ Graduated as a model family } & Yes & 331 & 1 & \\
\hline & No & 282 & $0.76(0.45,2.39)$ & 0.26 \\
\hline
\end{tabular}

${ }^{\mathrm{a}}$ Statistically significant at $\mathrm{p}<0.05$

\section{Conclusions}

The primary purpose of the study was to assess the role of HEWs in promoting and expanding $\mathrm{MCH}$ services, which in turn helps to improve child and maternal health outcomes. The result showed that Health Posts are important health care delivery settings and their share from the overall service delivery of ANC, Family planning and child treatment services were pivotal and HEWs can improve their role in the $\mathrm{MCH}$ service delivery in the district by delivering appropriate information about the different available services to the mothers at the community and household level.
Despite these facts, overall service coverage of ANC (four and more visits), delivery and PNC services were low in the district as compared to the national status (EDHS 2016); and the input of the HEWs, in this regard, was unsatisfactory. The number of home visits was also inadequate for the necessary support of the mothers. Therefore, in order to address these gaps and improve the role of HEWs in the delivery of $\mathrm{MCH}$ services, all concerned bodies, including federal, regional and local governments should support the efforts of HEWs and need to address the challenges for poor performance areas of the HEWs in MCH service delivery. 
Table 7 Determinant factors of good MCH service utilization status in Dale district, southern Ethiopia, 2015

\begin{tabular}{lllll}
\hline Variables & Category & Frequency & $\begin{array}{l}\text { AOR } \\
(95 \% \mathrm{Cl})\end{array}$ & $P$-value \\
\hline $\begin{array}{lllll}\text { Mother's educational } \\
\text { status }\end{array}$ & Illiterate & 143 & 1 & \\
& $\begin{array}{l}\text { Primary } \\
\text { education }\end{array}$ & 388 & $\begin{array}{l}2.37 \\
(0.72,7.78)\end{array}$ & 0.15 \\
& $\begin{array}{l}\text { Secondary } \\
\text { education }\end{array}$ & 68 & $\begin{array}{l}4.77 \\
(0.00,)\end{array}$ & 0.99 \\
& $\begin{array}{l}\text { Higher } \\
\text { education }\end{array}$ & 11 & $\begin{array}{l}0.52 \\
(0.23,1.18)\end{array}$ & 0.12 \\
& Yes & 269 & 2.09 & $0.03^{\mathrm{a}}$ \\
& & & $(1.06,4.14)$ & \\
Information delivery \\
by HEWs & No & 345 & 1 & \\
& Yes & 101 & 4.62 & $0.003^{\mathrm{a}}$ \\
Listen to the Radio & & $(1.66,12.85)$ & \\
& No & 492 & 1 & \\
\hline
\end{tabular}

${ }^{a}$ Statistically significant at $p<0.05$

The effect of the program on maternal and child health as well as the demand and supply side factors that influence $\mathrm{MCH}$ service utilization, should be studied in greater depth in future studies in order to improve the performance of the HEP continuously.

\section{Abbreviations}

AFI: Acute Febrile Illness; ANC: Ante-natal care; AOR: Adjusted odds ratio; CHWs: Community Health Workers; Cl: Confidence interval; COR: Crude odds ratio; EDHS: Ethiopian Demographic and Health Survey; HEP: Health Extension Program; HEWs: Health Extension Workers; HPs: Health Posts; MCH: Maternal and child health; PNC: Post-natal care

\section{Acknowledgements}

We would like to acknowledge Yirgalem Hospital Medical College for the financial support of this research. All the respondent mothers also deserve appreciation for their interest and patience to participate in the study.

\section{Availability of data and material}

The datasets generated during and/or analysed during the current study are available from the corresponding author on reasonable request.

\section{Funding}

This work was funded by Yirgalem Hospital Medical College. The funding body had no role in study design, data collection and analysis, decision to publish, or preparation of the manuscript.

\section{Authors' contributions}

AN and GG conceived, designed, analyzed the data and interpreted the results. AN prepared and critically reviewed the manuscript. All authors read and approved the manuscript.

\section{Ethics approval and consent to participate}

The study protocol was approved by Research Ethics Committee of Yirgalem Hospital Medical College. Written informed consent was secured from all mothers before their involvement in interviews.

\section{Consent for publication}

Not applicable.

\section{Competing interests}

The authors declare that they have no competing interests.

\section{Publisher's Note}

Springer Nature remains neutral with regard to jurisdictional claims in published maps and institutional affiliations.

Received: 8 October 2016 Accepted: 1 September 2017

Published online: 11 September 2017

\section{References}

1. Central Statistical Agency (CSA) [Ethiopia] and ICF. Ethiopia demographic and health survey 2016: key indicators report. Addis Ababa and Rockville: CSA and ICF; 2016.

2. Berhan Y, Berhan A. Causes of maternal mortality in Ethiopia: a significant decline in abortion related death. Ethiop J Health Sci. 2014;(Special Issue):15-28.

3. United Nations Children's Fund (UNICEF): Progress report: committing to child survival; 2012.

4. United Nations Children's Fund (UNICEF): Basic indicators; 2012.

5. WHO: Report 2012; 2012.

6. Federal Ministry of Health (Ethiopia). Health Sector Development Programme IV; Annual Performance Report, EFY 2003 (2010/11). Addis Ababa; 2010.

7. Federal Ministry of Health (Ethiopia). Health Extension Program in Ethiopia. Addis Ababa: Health Extension and Education Center; 2007.

8. Federal Ministry of Health (Ethiopia). The Health Service Before and after 1991: a summary of achievements from 1991 to 2010. Addis Ababa; 2010.

9. Ulin PR, Robinson ET, Tolley EE. Qualitative methods in public health: A field guide for applied research. San Francisco: Jossey-Bass; 2005.

10. U.S. Agency for International Development (USAID): Health extension program: an innovative solution to public health challenges of Ethiopia: a case study; 2012.

11. UN Inter-agency Group for Child Mortality Estimation (UN IGME): Levels \& trends in child mortality. Report 2013.2013.

12. Medhanyie, et al. The role of health extension workers in improving utilization of maternal health services in rural areas in Ethiopia: a cross sectional study. BMC Health Serv Res. 2012;12(352). doi:10.1186/1472-6963-12-352.

13. Amare SA. The impact of Ethiopian Health Services Extension Program on maternal and child health outcomes: the case of Tigray Region, Thesis: Georgia State University, Atlanta, Georgia; 2013.

14. Tesfa B, Jibat N. Health Extension Program as innovative health care service: the socio-cultural factors affecting its implementation in Jimma Zone, South Western Oromia. International Journal of Sociology and Anthropology. 2014;6(8):235-45.

15. Central Statistical Agency (Ethiopia) and ICF International, Macro ORC. Ethiopian Demographic and Health Survey 2011. Addis Ababa, Calverton, Maryland; 2012: Central Statistical Agency and ICF International.

16. Tropical Institute of Community Health and Development (TICH). An assessment on contribution of community strategy approach to Comprehensive Primary Health Care (CPHC) in Kenya: Great Lakes University of Kisumu (GLUK), Kisumu, Kenya; 2011.

17. Mitchel Group Inc: ACCESS/MCHIP Evaluation, USAID/Nigeriann; 2012.

18. Ramsey et al. The Tanzania Connect Project: a cluster randomized trial of the child survival impact of adding paid community health workers to an existing facility-focused health system. BMC Health Serv Res; 2013.
Submit your next manuscript to BioMed Central and we will help you at every step:

- We accept pre-submission inquiries

- Our selector tool helps you to find the most relevant journal

- We provide round the clock customer support

- Convenient online submission

- Thorough peer review

- Inclusion in PubMed and all major indexing services

- Maximum visibility for your research

Submit your manuscript at www.biomedcentral.com/submit
Biomed Central 